УДК 342.9

DOI https://doi.org/10.17308/vsu.proc.law.2021.2/3393

\title{
К ДИСКУССИИ О ПУБЛИЧНОМ ПОРЯДКЕ: СРАВНИТЕЛЬНО-ПРАВОВОЙ АНАЛИЗ ТЕОРИИ, ЗАКОНОДАТЕЛЬСТВА И СУДЕБНОЙ ПРАКТИКИ
}

\author{
Д. В. Уткин \\ Воронежский государственный университет \\ Поступила в редакцию 21 января 2021 г.
}

\begin{abstract}
Аннотация: рассматриваются проблемные аспекты понилания правовой категории "публичный порядок", исследуются законодательство и судебная практика, позволяющие сделать вывод об отсутствии единого понилания данной категории, предлагается понимание публичного порядка как адлинистративно-правового института, обеспечивающего законность в сббере государственного управления.

Ключевые слова: публичный порядок, общественный порядок, законность в сфере государственного управления, адлинистративное судопроизводство.
\end{abstract}

\begin{abstract}
: the article examines the problematic aspects of understanding the right category of "public order", examines the legislation and judicial practice, which make it possible to conclude that there is no common understanding of the category, suggests an understanding of public order as an administrative and legal institution that ensures the rule of law in the field of public administration. Key words: public order, legality in public administration, administrative justice.
\end{abstract}

Правовой институт публичного порядка, являясь по своей правовой природе публично-правовой категорией, никогда не рассматривался как таковой. Научный пробел исследования категории «публичный порядок» учеными школы публичного права, отсутствие научных трудов, в которых исследовалась бы государственно-правовая природа публичного порядка, привело к недостатку изученности данной проблемы и отсутствию надлежащего толкования данной правовой категории.

Анализ законодательства Российской Федерации и судебной практики позволяет сделать вывод об отсутствии единого понимания публичного порядка. Данная правовая категория фррагментарно прослеживается в федеральном законодательстве и в основном употребляется в контексте «оговорки о публичном порядке» в международном частном праве и гражданском процессе. Так, в ст. 1193 Гражданского кодекса РФ «Оговорка о публичном порядке» закреплено, что норма иностранного права, подлежащая применению, в исключительных случаях не применяется, когда последствия ее применения явно противоречили бы основам правопорядка (публичнолу порядку) Российской Федерации с учетом харак-

(с) Уткин Д. В., 2021 


\section{Вестник ВГУ. Серия: Право}

тера отношений, осложненных иностранным элементом ${ }^{1}$. Как видно из содержания данной правовой нормы, категория «публичный порядок» представлена в российском законодательстве через институт оговорки, предусматривающий отступление от правил международного частного права.

Дальнейшее закрепление категории «публичный порядок» прослеживается в российском процессуальном законодательстве. Статьей 417 Гражданского процессуального кодекса РФ установлены случаи отказа в признании и исполнении решения иностранного третейского суда, одним из которых является установление судом противоречия данного решения публичнолу порядку Российской Федерации ${ }^{2}$.

Такие же правила закреплены в Арбитражном процессуальном кодексе РФ. Так, арбитражный суд отказывает в признании и приведении в исполнение решения иностранного суда полностью или в части в случае, если исполнение решения иностранного суда противоречило бы $n y$ бличнолу порядку Российской Федерации (ст. 244 АПК РФ) ${ }^{3}$. Аналогичные нормы содержатся в Законе РФ от 7 июля 1993 г. «О международном коммерческом арбитраже» (ст. 34,36$)^{4}$.

Еще одним законодательным актом, в котором употребляется термин «публичный порядок», является Семейный кодекс РФ. Согласно ст. 167 СК РФ нормы иностранного семейного права не применяются в случае, если такое применение противоречило бы основам правопорядка ( $n y$ бличному порядку) Российской Федерации ${ }^{5}$ Таким образом, в настоящее время правовое обеспечение публичного порядка в основном прослеживается в сфере международного частноправового регулирования.

Категория «публичный порядок» также нашла свое отражение в действующем до настоящего времени постановлении ЦИК и СНК СССР от 7 августа 1937 г. «Положение о переводном и простом векселе» ${ }^{6}$, в котором говорится об акте, составленном в публичнол порядке. В данном нормативном акте говорится не как о системе публично-правовых отношений,

${ }^{1}$ Гражданский кодекс Российской Федерации (часть третья) : федер. закон от 26 ноября 2001 г. № 146-ФЗ (в ред. от 18.03.2019) // Собр. законодательства Рос. Федерации. 2001. № 49. Ст. 4552 ; 2019. № 12. Ст. 1224.

$116{ }^{2}$ Гражданский процессуальный кодекс Российской Федерации : федер. закон от 14 ноября 2002 г. № 138-ФЗ (в ред. от 08.12.2020) // Собр. законодательства Рос. Федерации. 2002. № 46. Ст. 4532 ; 2020. № 50 (ч. 3). Ст. 8073.

${ }^{3}$ Арбитражный процессуальный кодекс Российской Федерации : федер. закон от 24 июля 2002 г. № 95-ФЗ (в ред. от 08.12.2020) // Собр. законодательства Рос. Федерации. 2002. № 30. Ст. 3012 ; 2020. № 50 (ч. 3). Ст. 8073.

${ }^{4} \mathrm{O}$ международном коммерческом арбитраже : закон РФ от 7 июля 1993 г. № 5338-1 (в ред. от 25.12.2018) // Рос. газета. 1993. 14 авг.

${ }^{5}$ Семейный кодекс Российской Федерации : федер. закон от 29 декабря 1995 г. № 223-ФЗ (в ред. от 04.02.2021) // Собр. законодательства Рос. Федерации. 1996. № 1. Ст. 16 ; 2021 . № 6. Ст. 960.

${ }^{6} \mathrm{O}$ введении в действие Положения о переводном и простом векселе : постановление ЦИК СССР и СНК СССР от 7 августа 1937 г. № 104/1341 // Собр. законов и распоряжений Рабоче-крестьянского правительства СССР. 1937. № 52. Ст. 221. 
в которой соблюдаются законы и административные предписания, а как о способе составления публично-правового акта.

Неоднозначное видение "публичного порядка" прослеживается в судебной практике. Так, Верховный Суд РФ под публичнылм порядкол понимает фрундаментальные правовые начала (принципы), которые обладают высшей императивностью, универсальностью, особой общественной и публичной значимостью, составляют основу построения экономической, политической, правовой системы государства (п. 45) 7 . Одновременно с данной позицией в иных обзорах судебной практики можно встретить позицию высшей судебной инстанции, согласно которой проводится аналогия публичного и общественного порядка (п. 10) ${ }^{8}$. Кроме того, Верховый Суд РФ причинение ущерба публичнолу порядку определяет как вред, причиняемый общественным отношениям, и как элемент объективной стороны состава административного правонарушения (п. 26) ${ }^{9}$.

Проанализировав действующее законодательство Российской Федерации, в нормах которого неполно закреплена правовая категория «публичный порядок», напрашивается вывод, что законодательная власть так и не смогла нормативно установить содержание данной правовой категории. В связи с этим целью нашего исследования является изучение содержания публичного порядка с позиций публичного права, а именно административно-правового содержания публичного порядка.

Несмотря на образовавшийся научный вакуум в административно-правовом исследовании данной проблемы, учеными других отраслей права все же предпринята попытка анализа публичного порядка в международном праве, международном частном праве и гражданском процессе. Так, категория «публичный порядок» была косвенно затронута в диссертационном исследовании Р. Ш. Хасянова, который отмечает, что публичный порядок традиционно рассматривается в рамках частного права, что «не соответствует его природе, существу и фрункциям» ${ }^{10}$. Исследовав публичный порядок в международном праве и правовых системах государств, автор определяет международный и европейский публичный порядок как состояние правовой урегулированности отношений, харак-

${ }^{7}$ Обзор судебной практики Верховного Суда Российской Федерации № 5 (2017) : утв. Президиумом Верховного Суда РФ 27 декабря 2017 г. // Бюллетень Верховного Суда РФ. 2018. № 12.

${ }^{8}$ Обзор судебной практики Верховного Суда Российской Федерации № 1 (2016) : утв. Президиумом Верховного Суда РФ 13 апреля 2016 г. // Бюллетень Верховного Суда РФ. 2016. № 11-12.

${ }^{9}$ Обзор судебной практики Верховного Суда Российской Федерации № 4 (2017) : утв. Президиумом Верховного Суда РФ 15 ноября 2017 г. // Бюллетень Верховного Суда РФ. 2018. № 11.

${ }^{10}$ Хасянов Р. Ш. Европейский публичный порядок, европейское правовое пространство и Европейская конвенция о защите прав человека и основных свобод : их соотношение и взаимодействие : авторефр. дис. ... канд. юрид. наук. СПб., 2005. C. 9 . 
теризующееся определенной организованностью и упорядоченностью отношений всех участников межгосударственных отношений ${ }^{11}$.

Исследованием публичного порядка от буквального толкования этого термина до понимания его как правового института занимался С. В. Крохалев. Согласно его точке зрения, публичный порядок является универсальным и трансдисциплинарным понятием, а в его содержание входят высшие ценности, необходимые и фрундаментальные для конкретного общества ${ }^{12}$. Вместе с тем автор рассматривает публичный порядок как юридический механизм разрешения конфликтов, т. е. ограничивается его пониманием лишь в рамках гражданского процесса.

Правовое обеспечение публичного порядка в сфере международного частноправового регулирования исследовано также и другими авторами, полагающими, что под публичным порядком следует понимать «интегративные правила поведения, закрепленные в морально-нравственных традициях и ментальной природе общества, служащие регуляции соотношения частных и публичных интересов и сохранению целостности социальной общности» ${ }^{13}$.

Следует отметить недостаточность научных исследований, раскрывающих наиболее полное содержание категории «публичный порядок», а также исследование данной правовой категории лишь в контексте «оговорки о публичном порядке». Отсутствие четкого критерия для определения публичного порядка является основной проблемой для нормативного закрепления его содержания. В связи с этим возникает необходимость разграничивать категории публичного порядка и оговорки о публичном порядке, так как их содержательная сторона абсолютно разная. В содержание публичного порядка входят отношения по обеспечению надлежащей и эфррективной системы управленческих отношений внутри государства, в то время как оговорка о публичном порядке является одним из способов обеспечения публичного порядка.

Несомненно, представления о публичном порядке могут быть разными не только в большинстве стран, но и в пределах страны в разные годы исторического развития. Таким образом, неоднозначные научные доктрины об узком понимании публичного порядка как института международного права, ссылающиеся при этом на публично-правовое его происхождение, еще раз подчеркивают важность исследования публичного порядка как государственно-властного, административно-правового института, обеспечивающего законность в сфере государственного управления.

В современном правовом государстве обеспечение законности $u$ nyбличного порядка, защита прав и свобод граждан от незаконных дей-

${ }^{11}$ См.: Хасянов Р. ШI. С. 16.

${ }^{12}$ См.: Крохалев С. В. Категория публичного порядка в международном гражданском процессе. Сравнительное исследование на основе правовых систем России и Франции : авторефр. дис. ... канд. юрид. наук. Екатеринбург, 2005. С. 13.

${ }^{13}$ Гизетдинова И. Ю. «Публичный порядок» в международном частном праве : автореф. дис. ... канд. юрид. наук. М., 2009. С. 6-7. 
ствий (бездействия) органов власти и их должностных лии должны относиться к числу приоритетных фрункций государства.

Законность чаще всего рассматривается как общеправовой конституционный принцип. В соответствии с Конституцией РФ (ч. 2 ст. 15) органы государственной власти, органы местного самоуправления, должностные лица, граждане и их объединения обязаны соблюдать Конституцию РФ и законы. Классическое, достаточно простое и краткое определение законности дается в учебниках по теории государства и права как «строгое и неуклонное соблюдение всеми субъектами права существующих в стране законов и основанных на них подзаконных нормативных актов» ${ }^{14}$. Весьма схожие характеристики законности предложены также учеными в теории публичного управления, так как исполнение административных предписаний является основой публичного порядка и обеспечения законности ${ }^{15}$.

В целях обеспечения публичного порядка конституционное закрепление данного принципа позволяет установить пределы административного усмотрения властвующих субъектов. Усмотрение должностного лица должно иметь место лишь в пределах, установленных законом, т. е. основной целью правоприменительной деятельности должностных лиц государственной власти должно быть укрепление законности. Необходимо отметить, что одним из фракторов ограничения пределов государственной власти является развитие и защита прав и свобод граждан.

Защита прав человека является главным критерием современного правового государства, а защита прав и свобод граждан от незаконных действий (бездействия) органов власти и их должностных лиц - главным критерием обеспечения публичного порядка. Реализация данной конституционной гарантии обеспечивается системой органов судебной власти, правоохранительных органов, а также эфрфективным, как показала практика, административно-процессуальным законодательством. Принятие Кодекса административного судопроизводства РФ явилось важным этапом в развитии судебной системы страны, модернизации процессуального законодательства, устанавливающего специальный порядок разрешения административных дел и приведения правосудия в надлежащую структуру, соответствующую стандартам обеспечения прав, свобод, законных интересов фризических лиц и организаций.

Административное судопроизводство является способом рассмотрения споров между административными истцами (физическими и юридическими лицами) и административными ответчиками (государственными органами), в том числе об оспаривании незаконных действий (бездействия) последних. Вместе с тем российское административное судопроизводство предусматривает рассмотрение иных дел, совершенно противоположных, когда требования к физическому или юридическому

${ }^{14}$ Матузов Н. И., Малько А. В. Теория государства и права. М., 2004. С. 198.

${ }^{15}$ См.: Старилов Ю. Н. Вводные замечания // Шершеневич Г. Ф. О чувстве законности : публичная лекция, читанная 10 марта 1897 г. Воронеж, 2018. С. 5. 
лицу предъявляет государственный орган (дела о вынесении судебного приказа по требованиям о взыскании обязательных платежей и санкций), а также дел о разрешении споров между органами государственной власти.

Посредством административно-процессуальной формы ограничивается возможность управляющего воздействия государственных органов, органов местного самоуправления и должностных лиц на личность и общество, а также возможность ущемления ими законных прав и интересов граждан. Таким образом, административное судопроизводство является определенным препятствием для возможного произвола со стороны государственной власти и обеспечения публичного порядка и полноценным судебным контролем за действиями и решениями органов государственного управления и их должностных лиц, государственных и муниципальных служащих.

Термин «публичный» этимологически происходит от латинского слова "publicus", означающего общественный, государственный. Соответственно публичный порядок есть не что иное, как порядок общественный или государственный. При этом термин «общественный порядок» имеет конституционную основу и закрепление. Так, в ст. 114 Конституции РФ одним из основных полномочий Правительства РФ установлено принятие мер по охране общественного порядка. Исходя из содержания данной нормы видно, что конституционное понимание общественного порядка связано не с его социально-политическим значением, а употребляется в административном смысле как совокупность правил общественного порядка и поведения граждан. Основные функции по охране общественного порядка в основном возложены на правоохранительные органы.

Государственный же порядок регулируется правовыми нормами и $\sim$ правилами, устанавливающими организацию и деятельность государ이 ства, порядок деятельности органов государственной власти, осуществление законности в деятельности государственных (публичных) органов. Полномочия по защите государственного (публичного) порядка возлагаются на Президента РФ, органы законодательной, исполнительной, судебной власти и прокуратуры. Именно данный правопорядок понимает российский законодатель в правовых нормах, рассмотренных нами выше.

Классическая дихотомия данных терминов привела к тому, что в нормативном смысле общественный порядок и публичный порядок имеют законодательную основу, а в доктринальном подходе рассмотрены лишь правовые категории «общественный порядок» и «правопорядок», но не исследована правовая категории «публичный порядок».

В отечественной правовой науке категория «общественный порядок» понимается в широком и узком смысле. Общественный порядок в широком смысле представляет собой систему общественных отношений. Так, ряд ученых советского периода рассматривали общественный порядок как систему и упорядоченность общественных отношений, которые приводят к согласованности общественной жизни, реализации их участни- 
ками прав, обязанностей и защите интересов ${ }^{16}$; «систему общественных отношений, неприкосновенность которой гарантируется всей политической системой государства» ${ }^{17}$. Узкий подход к пониманию общественного порядка большинством ученых признается более приемлемым для российского законодательства. При этом общественный порядок представлен как совокупность общественных отношений, но связанных с поведением граждан в общественных местах.

Следует отметить, что категория «правопорядок» также не осталась без внимания многих ученых ${ }^{18}$ : за последние годы проводились круглые столы и научные дискуссии по данной тематике ${ }^{19}$. Так, под правопорядком понимают состояние упорядоченности общественных отношений, основанное на праве и законности.

Отсутствие доктринального толкования публичного порядка наравне с отсутствием четкого критерия для его определения является основной проблемой для нормативного закрепления его содержания. Таким образом, возникает необходимость разграничивать категории «публичный порядок» и «общественный порядок», в связи с разностью их содержания. В содержание публичного порядка входят отношения по обеспечению надлежащей и эффрективной системы государственных управленческих отношений внутри государства, по соблюдению публичными органами законодательных актов, административных предписаний и укреплению законности в их деятельности.

Правоотношения, возникающие в связи с государственным управлением, несомненно, носят публичный характер и являются публично-правовыми. В классическом понимании публичные правоотношения возникают между субъектами права, одним из которых является орган государственной власти, и возникают в связи с осуществлением функций и задач государства. Однако в реальности публичные правоотношения, так же как и другие общественные отношения, устанавливаются между людьми, осуществляющими властные функции, так как в «безличной форме власть не может являться реальным участником правоотношения» ${ }^{20}$. Однако требования правящих субъектов к гражданам выражаются не как частный интерес и могут иметь различный характер в зависимо-

${ }^{16}$ См.: Лазарев В. В., Попов Л. Л., Розин Л. М. Правовые основы обеспечения общественного порядка. М., 1987.

${ }^{17}$ Кондрашов Б. П. Общественная безопасность и административно-правовые средства ее обеспечения. М., 1998. С. 16.

${ }_{18}$ См.: Варлалова Н. В. Государство как правопорядок и правопорядок без государства // Труды института государства и права Российской академии наук. 2016. № 2. C. 89-114.

${ }^{19}$ См.: Залоило М. В., Козырева А. Б. Взаимосвязь российского правопорядка и правопорядка Совета Европы : материалы конференции // Актуальные проблемы российского права. 2015. № 6 (55). С. 214-218.

${ }^{20}$ Елистратов А. И. Основные начала административного права // Российское полицейское (административное) право : конец XIX - начало XX века : хрестоматия / сост. и вступ. слово Ю. Н. Старилова. Воронеж, 1999. С. 449. 
сти от степени административного усмотрения и правового регулирования деятельности властвующих.

Таким образом, под публичныли порядкол необходимо понимать систему публично-правовых отношений по реализации их участниками публичных правомочий и публично-правовых обязанностей, по соблюдению органами публичной власти законодательства и укреплению законности в их деятельности.

\section{Библиографический список}

Варлалова Н. В. Государство как правопорядок и правопорядок без государства / Н. В. Варламова // Труды института государства и права Российской академии наук. 2016. № 2. С. 89-114.

Гизетдинова И. Ю. «Публичный порядок» в международном частном праве : авторедр. дис. ... канд. юрид. наук. М., 2009. 29 с.

Елистратов А. И. Основные начала административного права // Российское полицейское (административное) право : конец XIX - начало XX века : хрестоматия / сост. и вступ. сл. Ю. Н. Старилова. Воронеж, 1999. С. 371-619.

Залоило М. В., Козырева А. Б. Взаимосвязь российского правопорядка и правопорядка Совета Европы // Актуальные проблемы российского права : материалы конфр. 2015. № 6 (55). С. 214-218.

Кондрашов Б.П. Общественная безопасность и административно-правовые средства ее обеспечения. М., 1998. 296 с.

Крохалев С. В. Категория публичного порядка в международном гражданском процессе. Сравнительное исследование на основе правовых систем России и Франции : автореф. дис. ... канд. юрид. наук. Екатеринбург, 2005. $30 \mathrm{c.}$

Лазарев В. В., Попов Л. Л., Розин Л. М. Правовые основы обеспечения общественного порядка. М., 1987. 75 с.

Матузов Н. И., Малько А. В. Теория государства и права. М., 2004.511 с.

Старилов Ю. Н. Вводные замечания // Шершеневич Г. Ф. О чувстве законности : публичная лекция, читанная 10 марта 1897 г. / вводные замечания Ю. Н. Старилова. Воронеж, 2018. 36 с.

Хасянов Р. Ш. Европейский публичный порядок, европейское правовое пространство и европейская Конвенция о защите прав человека и основных свобод : их соотношение и взаимодействие : автореф. дис. ... канд. юрид. наук. СПб., 2005. 24 с.

\section{References}

Varlamova N. V. The state as the legal order and the legal order without a state / N. V. Varlamova // Proceedings of the Institute of State and Law of the Russian Academy of Sciences. 2016. № 2. P. 89-114.

Gizetdinova I. Yu. "Public order» in private international law: specialty 12.00.03 «Civil law; business law; family law; private international law»: dissertation abstract for the degree of candidate of legal sciences. M., 2009. 29 p.

Elistratov A. I. Basic principles of administrative law // Russian police (administrative) law: Late XIX - early XX century: Chrestomathy / Comp. and introductory remarks by Yu. N. Starilova. Voronezh, 1999. P. 371-619. 
Zaloilo M. V., Kozyreva A. V. Interrelation between the russian legal order and legal order of the council of Europe: Conference materials // Actual problems of Russian law. 2015. № 6 (55). P. 214-218.

Kondrashov B. P. Public safety and administrative and legal means of ensuring it. M., 1998. 296 p.

Krokhalev S. V. Public order category in international civil procedure. Comparative research based on the legal systems of Russia and France: specialty 12.00.15 «Civil process; arbitration process»: dissertation abstract for the degree of candidate of legal sciences. Ekaterinburg, 2005. 30 p.

Lazarev V. V., Popov L. L., Rozin L. M. Legal basis for ensuring public order, M., 1987. $75 \mathrm{p.}$

Matuzov N. I., Malko A. V. Theory of state and law. M., 2004. 511 p.

Starilov Yu. N. Introductory remarks // Shershenevich G. F. On the Sense of Legality: Public Lecture given on March 10, 1897 / introductory remarks by Yu. N. Starilova. Voronezh, 2018. 36 p.

Khasyanov R. Sh. European public order, European legal space and the European Convention for the Protection of Human Rights and Fundamental Freedoms: their relationship and interaction: specialty 12.00.10 «International law; European law»: dissertation abstract for the degree of candidate of legal sciences. St. Petersburg, 2005. 24 p.

Воронежский государственный университет

Уткин Д. В., кандидат юридических наук, доцент кафедры организации судебной власти и правоохранительной деятельности

E-mail:dut@mail.ru
Voronezh State University

Utkin D. V., Candidate of Legal Sciences, Associate Professor of the Organization of Judicial Authority and Law Enforcement Activity Department

E-mail:dut@mail.ru 